\title{
A Cross-sectional Survey of Hypertension Diagnosis and Treatment Practices Among Physicians in Yaroslavl Region, Russia
}

\author{
Maria Mozheyko · Sergey Eregin · Alexey Vigdorchik · David Hughes
}

To view enhanced content go to www.advancesintherapy.com

Received: October 13, 2012 / Published online: November 27, 2012

( ) The Author(s) 2012. This article is published with open access at Springerlink.com

\section{ABSTRACT}

Introduction: In Russia, cardiovascular (CV) mortality is the leading cause of death. With the prevalence of hypertension in adults reaching $40 \%$, hypertension is a key priority for health authorities to improve its prevention, diagnosis, and treatment. This requires an evaluation of current clinical practices in order to develop specific improvement initiatives.

\author{
M. Mozheyko \\ Yaroslavl Regional Clinical Hospital of War Veterans, \\ Yaroslavl, Russia \\ S. Eregin \\ Yaroslavl Regional Clinical Hospital, Yaroslavl, Russia \\ A. Vigdorchik $(\bowtie)$ \\ Medical Project Manager, Novartis Pharma LLC, \\ Sadovnicheskaya str., 82/2, 115035 Moscow, Russian \\ Federation \\ e-mail: alexey.vigdorchik@novartis.com \\ D. Hughes \\ Novartis International AG, Basel, Switzerland
}

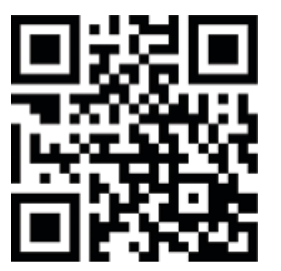

Enhanced content for Advances in Therapy articles is available on the journal web site: www.advancesintherapy.com
Methods: This cross-sectional survey was conducted in 39 outpatient institutions of Yaroslavl region from April to May 2011. A total of 180 physicians (154 general practitioners [GPs]; 26 cardiologists) completed diaries on 10 consecutive patients whose visits were related to hypertension. This survey was approved by the Department of Health and Pharmacy of Yaroslavl region.

Results: A total of 1,794 diaries (1,525 from GPs; 269 from cardiologists) were analyzed. The majority of patients were women (60\%), mean age was 60 years, and most (97\%) were on antihypertensive therapy. Mean blood pressure (BP) was 151/90 $\mathrm{mmHg}$ and goal BP (<140/90 mmHg) was achieved in $17 \%$ of patients. The distribution of patients' systolic BP (SBP) was: $20 \%$ controlled (<140 mmHg), 44\% SBP 140-159 $\mathrm{mmHg}$, 26\% SBP $160-179 \mathrm{mmHg}$, and 10\% SBP $\geq 180 \mathrm{mmHg}$. The most common CV risk factors included left ventricular hypertrophy (72\% of patients), abdominal obesity (54\%), dyslipidemia (48\%), family history of early CV events (33\%), smoking (24\%), and type 2 diabetes (21\%). Heart diseases and cerebrovascular diseases were reported in $48 \%$ and $15 \%$ of patients, respectively, and regular alcohol consumption was mentioned by $37 \%$. 
Conclusion: The majority of patients with hypertension had additional CV risk factors and associated clinical conditions. Blood pressure control rates in Yaroslavl region are similar to those for Russia as a whole, but much lower than countries that have successfully implemented comprehensive hypertension intervention programs, such as Canada.

Keywords: Blood pressure control; Cardiology; Diagnosis; Hypertension; Russia; Treatment

\section{INTRODUCTION}

Since the introduction of the Federal Target Program "Prevention and Treatment of Arterial Hypertension in the Russian Federation," the number of officially registered hypertensive patients has increased from slightly over 5 million in the year 2000 to almost 11.5 million in 2010 [1]. However, the actual number of hypertensive patients is estimated to be more than four times higher than the official registered number $[1,2]$. This high prevalence, coupled with suboptimal diagnosis and treatment, translates into very high levels of cardiovascular (CV) morbidity and mortality, accounting for $57 \%$ of all deaths in the country [1].

Mortality rates in 2010 in Russia from all CV diseases were 805.9 per 100,000 and were 1,009.1 per 100,000 in Yaroslavl region [1]. Because of this high CV mortality rate and the role of hypertension as the major risk factor for total mortality, our study was conducted with the goal of better understanding the current hypertension treatment practices [3].

The survey served as a basis for a coordinated program of interventions under the supervision of the Department of Health and Pharmacy, Yaroslavl Region to improve the prevention, diagnosis, and treatment of hypertension.

\section{METHODS}

A cross-sectional survey was conducted in 39 outpatient institutions of Yaroslavl region from April to May 2011. The sites were selected as a representative sample from the polyclinic institutions providing outpatient services in the Yaroslavl region. The final list of participating sites was approved by the Department of Health and Pharmacy of the Yaroslavl region. All selected sites participated. The 154 GPs and 26 cardiologists participating were asked to prospectively complete observational diaries on 10 consecutive adult patients (men and women $\geq 18$ years of age) whose visits were related to hypertension. This patient population is representative of those patients who seek medical help from outpatient departments on a regular basis. Only epidemiological survey methods were used for data collection. No additional examinations, tests, interventions, or specific procedures were performed during data collection. Only medical data in the patient's outpatient record and obtained during a routine examination at the visit were anonymously recorded and analyzed. The survey was initiated and approved by the Department of Health and Pharmacy of Yaroslavl region as a part of the Plan of Actions of Modernization of Cardiology and General Medicine Service of Yaroslavl region based on a memorandum of understanding between the Government of Yaroslavl region and Novartis Pharma LLC, Russia, on Cooperation in the Field of Public Health and Medical Science as of September 7, 2010.

\section{RESULTS}

A total of 1,794 patient diaries (1,525 from GPs; 269 from cardiologists) were collected and analyzed. Among all patients, this was a first visit for hypertension for $8 \%$ of patients 
(termed "primary patients"). Reasons for the present visit for all patients and primary patients are presented in Fig. 1a and 1b, respectively. For all patients, the most common reasons were headache (68\%) and planned visit (59\%); for primary patients, the most common reasons were headache $(62 \%)$

(a)

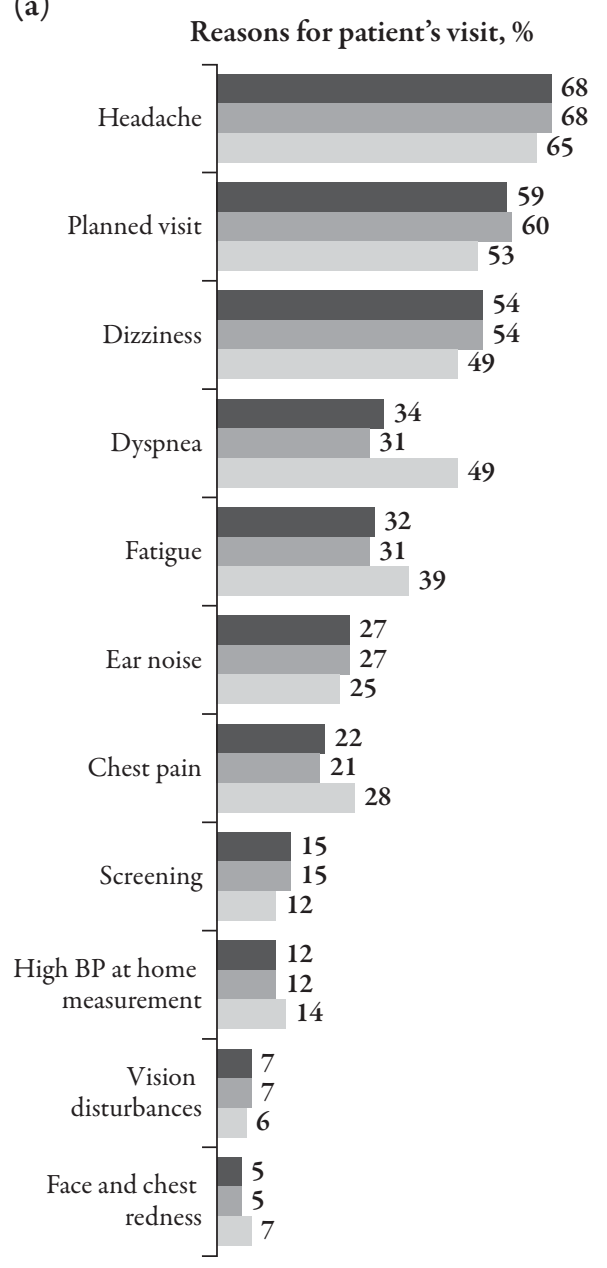

All physician's patients $(n=1,794)$

GPs' patients $(n=1,525)$

Cardiologists' patients $(n=269)$ and high self-measured home BP (49\%). Physicians' actions for primary patients are presented in Fig. 1c. Most (78\%) received a prescription for antihypertensive therapy, and a hypertension diagnosis was established in almost two-thirds of patients (63\%).

(b)

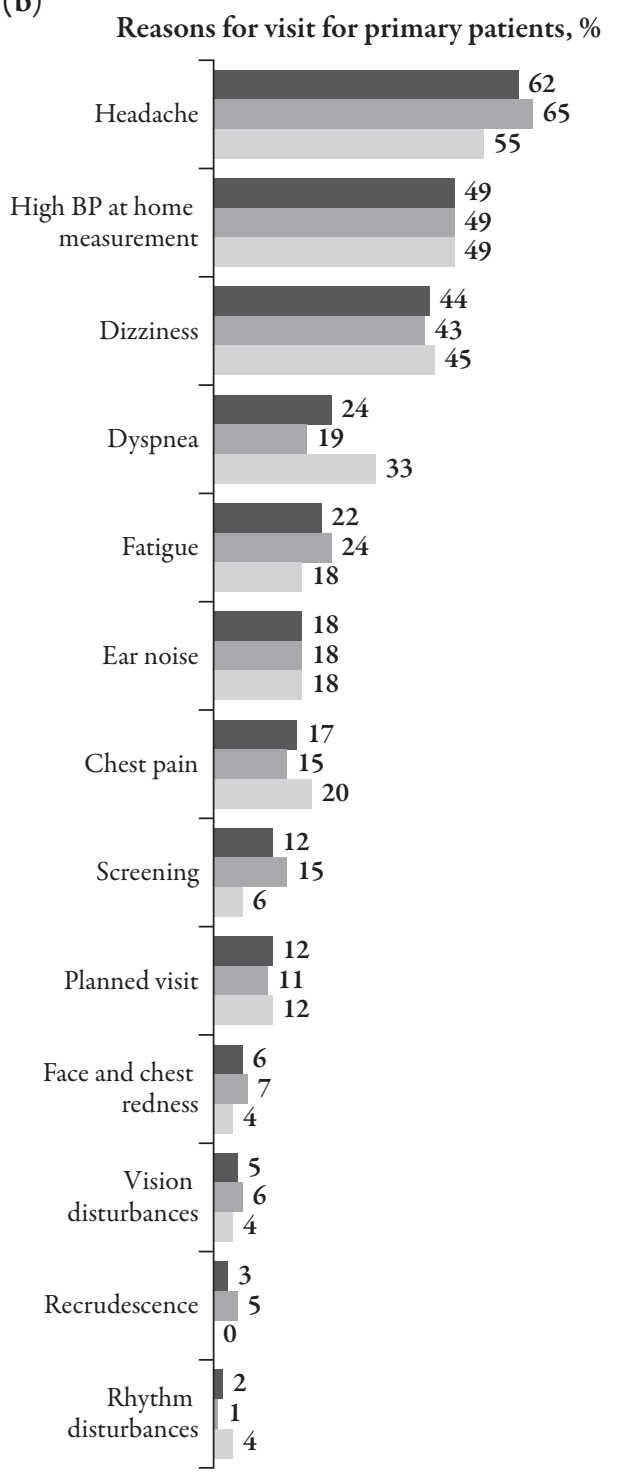

All physician's primary patients $(n=138)$

GPs' primary patients $(n=89)$

Cardiologists' primary patients $(n=49)$

Fig. 1 (a) Reasons for the patient's visit $(n=1,794)$; (b) Reasons for the patient's visit for primary patients $(n=138)$; (c) Physicians' actions during the initial visit for primary patients $(n=138)$. Values shown are $\%$ of patients. BP blood pressure, GPs general practitioners (continued on next page) 


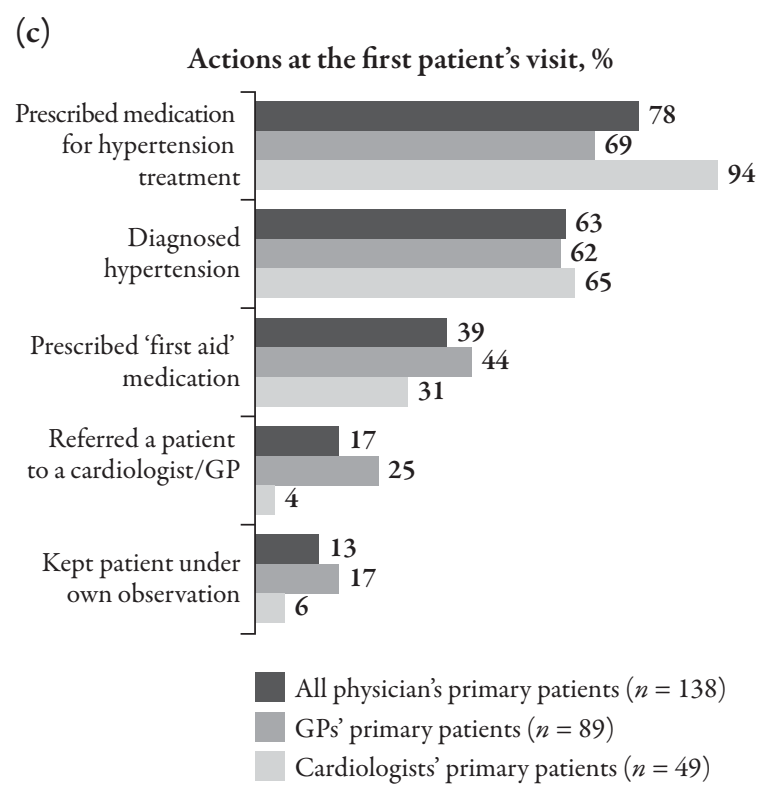

Fig. 1 continued

Demographics and hypertension history are presented in Table 1 . The majority of patients were women, the mean age was 60 years, and half were of working age according to Russian standards $(<60$ years for men and $<55$ years for women). The frequencies of risk factors, end organ diseases, and associated clinical conditions are also presented in Table 1. The majority of patients had left ventricular hypertrophy (72\%; determined by electrocardiography [ECG] or echocardiography), abdominal obesity (54\%), and dyslipidemia (48\%), as well as various forms of heart disease (48\%). Available laboratory test data are presented in Table 2 . The population can be characterized as having a high CV risk profile. Mean BP level was $151 / 90 \mathrm{mmHg}$ and mean heart rate was $74 \mathrm{bpm}$. Goal BP level $(<140 / 90 \mathrm{mmHg}$; set by the 2010 Russian National Guidelines [4]) was achieved in $16.8 \%$ of all patients (Fig. 2). Distribution of patients according to systolic BP (SBP) level is also presented in Fig. 2, with most patients in the 140-159 $\mathrm{mmHg}$ range.
Antihypertensive medications were recorded as an ongoing therapy at the moment of observation and are presented in Fig. 3 . A total of $97 \%$ of patients had antihypertensive medications prescribed, with $83 \%$ on a combination therapy. Only $23 \%$ of all patients were taking fixed-dose combinations, with 59\% taking free-dose combinations of antihypertensive medications. Beta-blockers were used in $50 \%$ of all patients, angiotensinconverting enzyme (ACE) inhibitors in 49\%, and diuretics in $40 \%$. Calcium channel blockers (CCBs) and angiotensin receptor blockers (ARBs) were used less frequently (in $26 \%$ and $16 \%$ of patients, respectively).

For all patients, the most frequently used agents in each major class were: beta blocker, bisoprolol (used in 38\% of patients; mean dose of $5.6 \mathrm{mg} /$ day) and metoprolol (9\%; $98.2 \mathrm{mg} /$ day); ACE inhibitor, perindopril (19\%; $5.0 \mathrm{mg} /$ day) and enalapril (14\%; $24.0 \mathrm{mg} /$ day); diuretic indapamide (34\%; $2.2 \mathrm{mg} /$ day); CCB amlodipine (22\%; $10.0 \mathrm{mg} /$ day); and ARB losartan (13\%; $49.6 \mathrm{mg} /$ day). Of note, although US and UK guidelines do not include beta blockers as first-line treatment for uncomplicated hypertension $[5,6]$, Russian $[4,7,8]$, and European $[9,10]$ guidelines consider them one of the five major treatment classes for first-line treatment of hypertension.

\section{DISCUSSION}

According to the latest reports from the 10-year Federal Program "Prevention and Treatment of Arterial Hypertension in the Russian Federation," the prevalence of hypertension in Russia has remained fairly constant at $39.7 \%$ and patient awareness is $81.2 \%$ [2]. Although the treatment rate is $66.1 \%$, BP control $(<140 / 90 \mathrm{mmHg})$ is achieved by only $23.9 \%$ of those treated (equal to $14.9 \%$ of all hypertension patients) [2]. 
Table 1 Demographics, hypertension history, patient risk factors, end organ disease, and associated clinical conditions

\begin{tabular}{llll}
\hline & $\begin{array}{l}\text { All physicians' patients } \\
(n=1,794)\end{array}$ & $\begin{array}{l}\text { GPs' patients } \\
(n=1,525)\end{array}$ & $\begin{array}{l}\text { Cardiologists' patients } \\
(n=269)\end{array}$ \\
\hline $\begin{array}{l}\text { Men/women/not specified, \% } \\
\text { Mean age, years }\end{array}$ & $37 / 60 / 3$ & $35 / 62 / 3$ & $44 / 52 / 4$ \\
Patient distribution by age group (years), \% & 61 & 58 \\
$<50$ & 60 & & \\
$50-59$ & 34 & 18 & 21 \\
$60-69$ & 25 & 32 & 40 \\
$\geq 70$ & 23 & 25 & 22 \\
Working age population $^{\mathrm{a}}$ & 50 & 24 & 16 \\
\end{tabular}

Patient distribution by duration of hypertension and hospitalization (years), \%

$\begin{array}{llll}\leq 1 & 18 & 16 & 30 \\ 2-9 & 40 & 41 & 35 \\ \geq 10 & 42 & 43 & 35 \\ \text { History of hospitalization due to } & 42 & 45 & 25\end{array}$

hypertension

Patient distribution by risk factors, end organ disease, and associated clinical conditions, $\%$

$\begin{array}{llll}\text { Left ventricular hypertrophy } & 72 & 72 & 72\end{array}$

$\begin{array}{llll}\text { Abdominal obesity } & 54 & 53 & 59\end{array}$

$\begin{array}{llll}\text { Dyslipidemia } & 48 & 46 & 58\end{array}$

$\begin{array}{llll}\text { Regular alcohol consumption } & 37 & 36 & 46\end{array}$

$\begin{array}{llll}\text { Family history of premature CVD } & 33 & 32 & 42\end{array}$

$\begin{array}{llll}\text { Patient smokes or smoked before } & 24 & 23 & 26\end{array}$

$\begin{array}{llll}\text { Diabetes type 2 } & 21 & 22 & 13\end{array}$

$\begin{array}{llll}\text { Carotid artery changes } & 17 & 14 & 34\end{array}$

$\begin{array}{llll}\text { Microalbuminuria } & 3 & 3 & 4\end{array}$

$\begin{array}{llll}\text { Heart diseases } & 48 & 47 & 57\end{array}$

$\begin{array}{llll}\text { Chronic heart failure } & 38 & 37 & 45\end{array}$

$\begin{array}{llll}\text { Angina pectoris } & 29 & 28 & 36\end{array}$

$\begin{array}{llll}\text { Myocardial infarction } & 11 & 10 & 19\end{array}$

$\begin{array}{llll}\text { Hypertensive retinopathy } & 20 & 20 & 14\end{array}$

$\begin{array}{llll}\text { Cerebrovascular diseases } & 15 & 16 & 12\end{array}$

$\begin{array}{llll}\text { Stroke } & 6 & 6 & 7\end{array}$

$\begin{array}{llll}\text { TIA } & 6 & 6 & 4\end{array}$

$\begin{array}{llll}\text { Peripheral artery disease } & 6 & 6 & 6\end{array}$

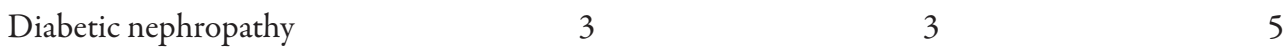

CVD cardiovascular disease, GP general practitioner, TIA transient ischemic attack

${ }^{\mathrm{a}}$ In Russia: $<60$ years for men and $<55$ years for women 
Table 2 Blood biochemistry

\begin{tabular}{llll}
\hline & \multicolumn{2}{l}{ Mean level (number of patients with available test record in chart) } \\
\cline { 2 - 4 } & All physicians' patients & GPs' patients & Cardiologists' patients \\
\hline Total cholesterol (mmol/L) & $5.5(n=1,501)$ & $5.5(n=1,261)$ & $5.5(n=240)$ \\
LDL cholesterol $(\mathrm{mmol} / \mathrm{L})$ & $3.1(n=628)$ & $3.1(n=490)$ & $3.1(n=138)$ \\
HDL cholesterol $(\mathrm{mmol} / \mathrm{L})$ & $1.7(n=519)$ & $1.7(n=394)$ & $1.3(n=125)$ \\
Triglycerides $(\mathrm{mmol} / \mathrm{L})$ & $1.8(n=546)$ & $1.9(n=415)$ & $1.7(n=131)$ \\
Fasting glucose level $(\mathrm{mmol} / \mathrm{L})$ & $5.4(n=1,614)$ & $5.4(n=1,387)$ & $5.2(n=227)$ \\
Uric acid $(\mathrm{mcmol} / \mathrm{L})$ & $260.4(n=360)$ & $257.9(n=312)$ & $276.8(n=48)$ \\
Creatinine $(\mathrm{mcmol} / \mathrm{L})$ & $87.4(n=1,140)$ & $87.4(n=973)$ & $87.7(n=167)$ \\
\hline
\end{tabular}

$G P$ general practitioner, $H D L$ high-density lipoprotein, $L D L$ low-density lipoprotein

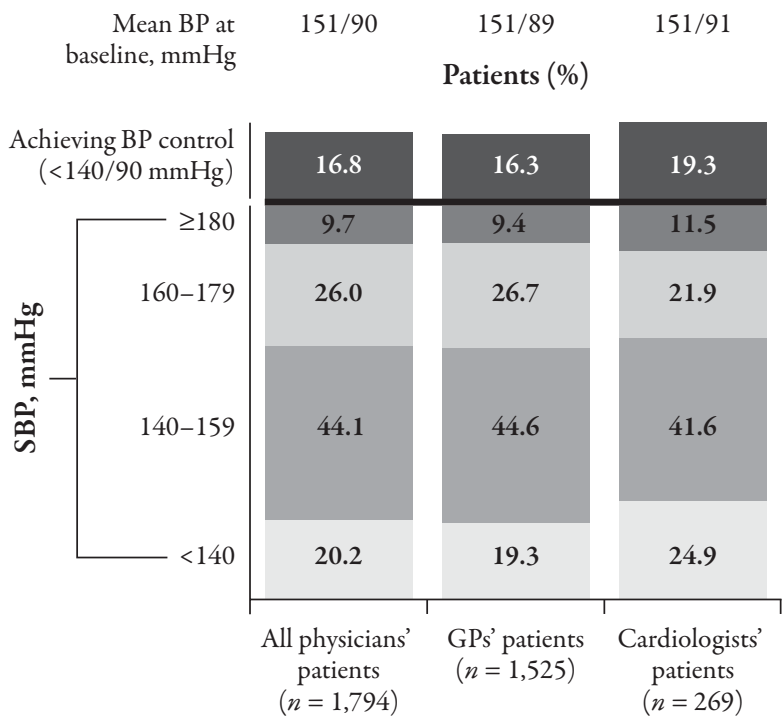

Fig. 2 Blood pressure control $(<140 / 90 \mathrm{mmHg})$ rates and systolic blood pressure levels $(n=1,794)$. BP blood pressure, GPs general practitioners, $S B P$ systolic blood pressure

An evaluation of hypertension treatment practices dedicated to pharmacotherapy quality across 13 regions showed that as many as $64 \%$ of hypertension patients did not have any antihypertensive prescription specified in their outpatient record, only 39\% had all necessary data for CV risk assessment, and 31\% had direct indications for antihypertensive therapy $[7,8]$.
The main analysis of this registry demonstrated that only $6.5 \%$ of patients had been prescribed antihypertensive medications that completely satisfied all criteria of the 2004 Russian National Hypertension Guidelines [7, 8].

CV mortality, especially mortality from cerebrovascular disease, remains excessively high in Russia, as well as in Yaroslavl region [1]. As hypertension is considered the most important risk factor for total and CV mortality, there was a clear demand for baseline research evaluating hypertension management practices in this region in order to inform design and implementation of clinical measures dedicated to improving $\mathrm{BP}$ control and reducing CV-related morbidity and mortality [3, 4].

For comparison, hypertension and CV epidemiology findings from Canada (2007-2009 survey) [11] show major differences from Russia with respect to prevalence of hypertension (19\% of the Canadian adult population), and high rates of treatment (80\%) and control (66\%). The most recent analysis of Canadian hypertension survey (2011) revealed that although the prevalence of hypertension has not changed for almost two decades, rates of patient awareness, hypertension treatment, and control have 

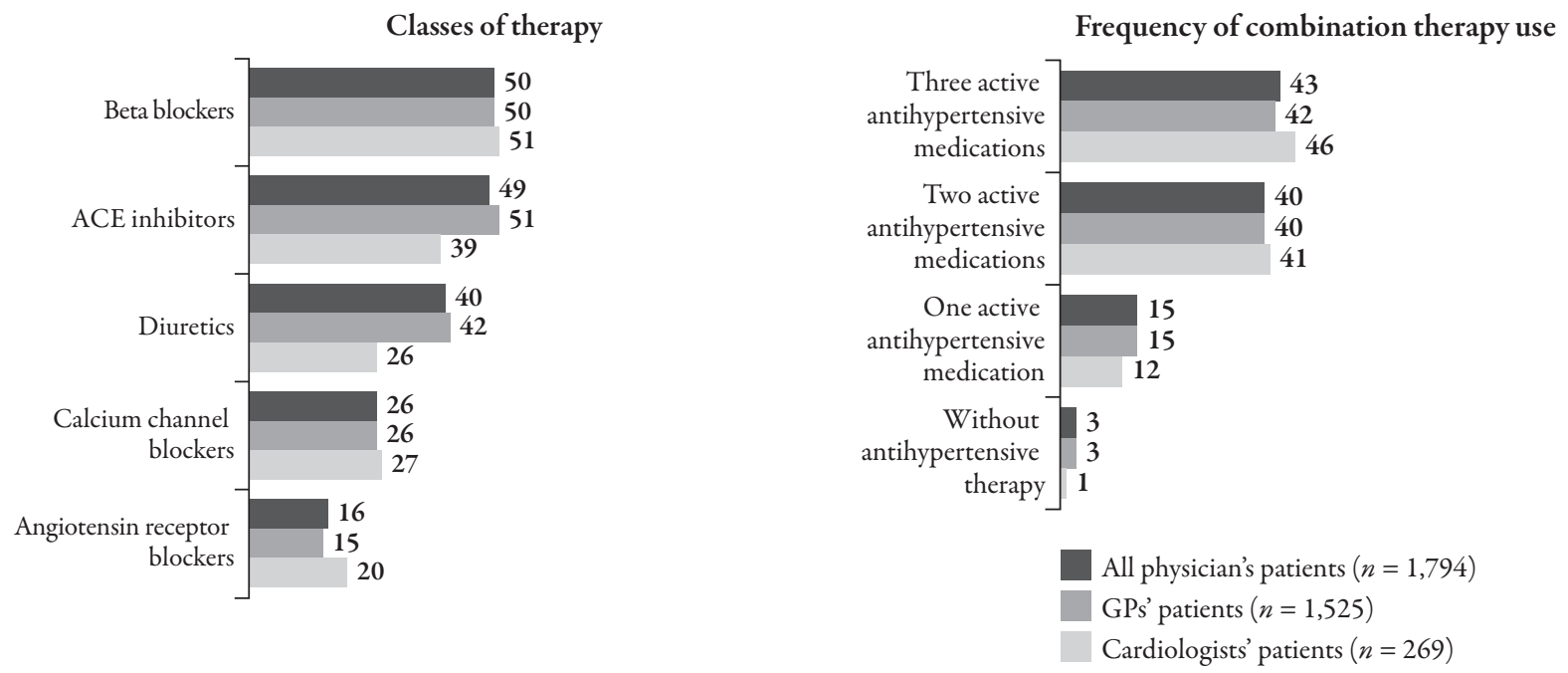

Fig. 3 Major classes of antihypertensive medications and frequency of combination therapy $(n=1,794)$. Values shown are $\%$ of patients. $A C E$ angiotensin-converting enzyme, GPs general practitioners

increased significantly [12]. The latest statistics released on the leading causes of death in Canada show that from 2000 to 2009, the largest relative decreases were in age-standardized rates for heart diseases and stroke, which both fell by $33 \%$ [13]. The age-standardized cerebrovascular disease (stroke) death rate was reported as 28.4 per 100,000 for 2009 , which is more than nine times lower than that in Russia during the same time period [1, 13].

Hypertension treatment practices have also been extensively studied in the Czech Republic [14, 15]. Cardiovascular risk factors were evaluated over the 22-23 years from the World Health Organization (WHO) MONICA (MONItoring trends and determinants in CArdiovascular disease) survey (1985) to the most recent $(2007 / 2008)$ [15]. Over this time period, both mean SBP and diastolic blood pressure (DBP) decreased for both men (135.8/85.9 $\mathrm{mmHg}$ to $132.5 / 84.4 \mathrm{mmHg})$ and women (131.6/82.5 mmHg to $126.7 / 80.6$ $\mathrm{mmHg}$ ), although only women experienced a decline in hypertension prevalence (43\% to $37 \%)$. Rates of hypertension awareness increased (men, 41-68\%; women, 59-71\%), as did rates of treatment (men, 21-58\%; women, 39-59\%), resulting in improved levels of hypertension control (men, 3-24\%; women, 5-25\%). This improvement in $\mathrm{CV}$ risk factors, especially hypertension, could explain the observed reductions in $\mathrm{CV}$ death rates, and particularly those for cerebrovascular diseases, in the Czech Republic over the last couple of decades [15].

Our research focused on the evaluation of current hypertension treatment practices and their effectiveness in Yaroslavl region, in order to plan actions that will address gaps in hypertension management. Specifically studied was the population of patients suffering from hypertension, as national epidemiological studies have reported all-Russia rates of hypertension prevalence, patient awareness, hypertension treatment, and control [2]. The main finding of fairly low $\mathrm{BP}$ control rates among treated patients $(16.8 \%)$ is consistent with results from the 2010 all-Russian nationwide survey (23.9\%) [2].

The high CV risk profile of the observed population is highly representative of the 
majority of patients seen by physicians in Russia. In the current survey, over $40 \%$ of patients were in the SBP range of $140-159 \mathrm{mmHg}$, and SBP was not controlled in approximately $80 \%$ of patients. These results demonstrate a large gap in the effectiveness of physicians and their patients in addressing hypertension as a known, treatable risk factor. A similar situation existed in Canada in the beginning of the 1990s, when BP control rates were approximately $13 \%$ [12].

One of the reasons that could explain the low level of BP control is underdosing of recommended therapies. The analysis of patients' prescriptions demonstrated that the most often used beta-blocking drug (bisoprolol $5.6 \mathrm{mg} /$ day) and the most often used ACE inhibitor (perindopril, $5.0 \mathrm{mg} /$ day) were dosed at what is considered to be the starting dose in hypertension management, in accordance with guidelines. It is likely that physicians continued to prescribe low-dose combination therapy without an up-titration when BP control was not achieved (as is recommended by guidelines) $[4,9,10]$.

Other factors that could explain the low level of BP control include the high frequency of comorbidities seen in the sample population, as well as the infrequent use of fixed-dose combinations. The relatively infrequent use of fixed-dose combinations observed is compounded by the fact that the physician-preferred combination of a beta-blocker and ACE inhibitor has no fixeddose combinations registered in Russia. This combination, compared with other combinations, is considered possible (but not rational) according to Russian guidelines [4] and is not recommended according to European guidelines [9, 10]. In addition, the most frequently used diuretic in our survey was indapamide at mean doses $>2 \mathrm{mg}$, which is rarely found in single-pill combinations.

Despite the availability of comprehensive Russian national guidelines for hypertension diagnosis and treatment [4], they are not consistently followed in clinical practice. The Canadian Hypertension Education Program (CHEP) [16, 17], initiated in Canada in 1999, has been successful in increasing hypertension treatment and control rates. This program includes three task forces: (1) a clinical recommendations task force that uses a rigorous and systematic process for developing recommendations, which are regularly updated; (2) an implementation task force that implements these recommendations by developing recommendation summaries and key prevention and control messages, with dissemination tailored to suit various audiences; and (3) an outcomes research task force to assess the success of the recommendations and identify areas for improvement. This approach to facilitating implementation of recommendations by clinicians should be the foundation of hypertension management programs for Russia and other countries with less-than-optimal hypertension control rates. Therefore, based on the experience with CHEP (where the intensity of treatment correlated with mortality reductions), implementation of a guidelines-based approach that highlights the necessity for effective combinations in effective doses to achieve BP control, and a need to advocate for patients' adherence to therapy, will improve control rates and decrease morbidity and mortality due to heart diseases and cerebrovascular diseases.

\section{Limitations}

Our survey has an obvious limitation of having a one-time, cross-sectional design. Physicians provided information on their own patients, which could have been a source of observer bias. In addition, although patients were representative of those who seek medical help from outpatient departments on a regular basis, they may not be representative of the entire population of hypertensive patients in the 
region, as the level of under-diagnosis in the country is quite large. Another limitation is that BP measurements could not be standardized, as this was a survey and not a clinical study, although it should be noted that the BP measurement was the one that the physician used for the patient's chart registration, and therefore to guide their clinical decision making. The cross-sectional design does not allow for the evaluation of the duration of treatment and its correlation to BP control. Regardless, we feel that the data obtained represent the "reallife" situation in primary care practice, as the high-risk profile of patients was reflected in the type of agents prescribed and the frequency of combination therapy. The purpose of this survey was to establish a baseline for an annual process of monitoring primary care physicians' hypertension management practices, which will allow for the tracking of changes during the ongoing hypertension improvement project established in Yaroslavl region in 2011.

\section{CONCLUSION}

$\mathrm{CV}$ diseases remain the leading cause of death in Russia. Hypertension, the most prevalent CV disease, is a major contributor to extremely high morbidity and mortality rates. The majority of patients with hypertension in Yaroslavl region who were being seen by physicians had additional risk factors and associated clinical conditions. Blood pressure control rates in Yaroslavl region are similar to those for Russia as a whole, but much lower than countries that have successfully implemented comprehensive hypertension intervention programs, such as Canada. Utilizing an approach similar to CHEP (including surveys over time to track BP control rates and national/regional statistical analyses to evaluate morbidity rates) will encourage use of the Russian National Guidelines and provide systematic feedback on the subsequent effects. With GPs comprising the majority of physicians in Yaroslavl region, they are integral in this process.

\section{ACKNOWLEDGMENTS}

This survey was initiated by the Department of Health and Pharmacy of Yaroslavl region, designed and reviewed by all authors, conducted by the International Institute for Market Research GFK Rus, and funded by Novartis International AG, Basel, Switzerland. The draft manuscript was prepared by Alexey Vigdorchik with input from M. Mozheyko, S. Eregin, and D. Hughes. Sponsorship and article processing charges were funded by Novartis International AG, Basel, Switzerland. Alexey Vigdorchik is the guarantor for this article, and takes responsibility for the integrity of the work as a whole.

The authors would like to thank Olga Chernichenko, Andrey Karasev, and Ekaterina Germanova, of International Institute for Market Research GFK Rus, for assistance in planning, conducting, and preliminary analysis of the present survey. Writing assistance, supported by Novartis International AG, Basel, was provided by Fran Karo, PhD, CMPP, of Oxford PharmaGenesis.

Conflict of Interest. Maria Mozheyko has received lecturer's honoraria and participated in research conducted by Novartis Pharma LLC Russia. Sergey Eregin has received lecturer's honoraria from Novartis Pharma LLC Russia. Alexey Vigdorchik is an employee of Novartis Pharma LLC, Russia. David Hughes is an employee of Novartis International AG, Switzerland.

Prior Presentation of Data. Results of this survey were presented, in part, at the AllRussian Scientific and Practical Conference "Noninfectious diseases and health of Russian population," May 17-18 2012, Moscow, Russia 
(Mozheyko ME, Eregin SY, Kagramanyan IN, Vigdorchik AV, Belyaevskaya VA, Hughes DL. Real life practice evaluation of hypertension patients' management by physicians of Yaroslavl Region, Preventive Medicine, 2012, V. 15, 2(2):95-96).

Open Access. This article is distributed under the terms of the Creative Commons Attribution Noncommercial License which permits any noncommercial use, distribution, and reproduction in any medium, provided the original author(s) and source are credited.

\section{REFERENCES}

1. Healthcare in Russia [Russian]. Moscow: Russian Federal Service of State Statistics; 2011:326. Available at: http://www.gks.ru. Accessed Oct 42012.

2. Oganov RG, Timofeeva TN, Koltunov IE, et al. Arterial hypertension epidemiology in Russia; the results of 2003-2010 federal monitoring. Cardiovascular Ther Prev. 2011;10:9-13.

3. Ezzati M, Lopez AD, Rodgers A, et al. Selected major risk factors and global and regional burden of disease. Lancet. 2002;360:1347-60.

4. Chazova IE, Ratova LG, Boytsov SA, et al, for the Experts Committee, Russian Medical Society of Arterial Hypertension and Russian Scientific Society of Cardiology. Diagnostics and treatment of arterial hypertension. Russian Guidelines (4th review). System Hypertension. 2010;3:5-26.

5. The Seventh Report of the Joint National Committee on Prevention, Detection, Evaluation, and Treatment of High Blood Pressure: The JNC 7 Report. JAMA. 2003;289:2560-72.

6. NCGC National Clinical Guideline Centre. Update of clinical guidelines 18 and 34. Hypertension: the clinical management of primary hypertension in adults. Clinical guideline 127 web site. http://www. nice.org.uk/nicemedia/live/13561/56007/56007.pdf. Updated August 2011. Accessed Nov 132012.

7. Posnenkova OM, Kiselev AR, Gridnev VI, et al. Pharmacotherapy quality in patients with arterial hypertension observed in primary care practice. Hypertension register data. Rational Pharmacother Cardiol. 2011;7:725-32.
8. Experts Committee of the Russian Scientific Society of Cardiology, Section of Arterial Hypertension. Prevention, diagnostics and treatment of arterial hypertension. Russian Guidelines (2nd review). Russian Scientific Society of Cardiology: Moscow, Russia. 2004;18:1-18

9. Mancia G, De Backer G, Dominiczak A, et al. 2007 Guidelines for the management of arterial hypertension: the Task Force for the Management of Arterial Hypertension of the European Society of Hypertension (ESH) and of the European Society of Cardiology (ESC). Eur Heart J. 2007;28:1462-536.

10. Mancia G, Laurent S, Agabiti-Rosei E, et al. Reappraisal of European guidelines on hypertension management: a European Society of Hypertension Task Force document. J Hypertens. 2009;27:2121-58.

11. Wilkins K, Campbell NR, Joffres $\mathrm{MR}$, et al. Blood pressure in Canadian adults. Health Rep. 2010;21:37-46.

12. McAlister FA, Wilkins $\mathrm{K}$, Joffres $\mathrm{M}$, et al. Changes in the rates of awareness, treatment and control of hypertension in Canada over the past two decades. CMAJ. 2011;183:1007-13.

13. Leading causes of death, 2009. Statistics Canada. 2012 July 25. Available at: http://www.statcan. gc.ca/daily-quotidien/120725/dq120725b-eng.htm. Accessed Oct 42012.

14. Cífková R, Škodová Z, Lánská V, et al. Prevalence, awareness, treatment, and control of hypertension in the Czech Republic. Results of two nationwide cross-sectional surveys in 1997/1998 and 2000/2001, Czech Post-MONICA Study. J Hum Hypertens. 2004;18:571-9.

15. Cífková R, Škodová Z, Bruthans J, et al. Longitudinal trends in major cardiovascular risk factors in the Czech population between 1985 and 2007/8. Czech MONICA and Czech post-MONICA. Atherosclerosis. 2010;211:676-81.

16. Campbell NR, Brant $\mathrm{R}$, Johansen $\mathrm{H}$, et al, for the Canadian Hypertension Education Program Outcomes Research Task Force. Increases in Antihypertensive Prescriptions and Reductions in Cardiovascular Events in Canada. Hypertension. 2009;53:128-134.

17. Campbell NRC, Tobe S. The Canadian effort to prevent and control hypertension: can other countries adopt Canadian strategies? Curr Opin Cardiol. 2010;25:366-72. 